\title{
Impacto de la migración de salvadoreños a los Estados Unidos, el envío de remesas y consecuencias en la estructura familiar y el papel de la mujer ${ }^{\star *}$
}

Segundo Montes

\section{Introducción y metodologia}

La investigación que realizamos durante un año con salvadoreños emigrados a los Estados Unidos y con sus familiares en El Salvador (Montes, 1987), presenta un estudio exploratorio del problema, arrojando cifras y características muy importantes del fenómeno, tanto en la cantidad de emigrados, como en la edad y nivel educativo, remesas que envian a sus familiares, destino que dan a ese dinero, deseos de retornar, e indicios de posible desintegración familiar, entre otros aspectos del problema.

La Unidad de Desarrollo Social de la Comisión Económica para América Latina y el Caribe (CEPAL) de las Naciones Unidas, en la Subsede de México, a través de su Jefe, Nguyen Huu Dong, me solicitó nuevos datos para conocer algunas consecuencias del fenómeno, que eran del interés de la CEPAL, como las diferencias que puedan existir si el jefe de familia es el varón o la mujer, si el destino de las remesas es para fines privados (nutrición, educación, etc.) o también sociales (ahorro, inversión, etc.), cambios en los niveles de vida y consumo o en actividades productivas, sobre todo en el sector informal, asi como posibles cambios en la estructura familiar y en el papel que desempeña

* Trabajo electuado para la CEPAL, y que sirvió de insumo para el documento "Las remesas, la economla familiar y el papel de la mujer: el caso de EI Salvador" (LC/MEX/L.91). Se publica con la autorización de la CEPAL. 
la mujer.

Como en la investigación anterior no habia datos que pudieran dilucidar esos interrogantes, se me solicitó una pequefa investigación, como "trabajo piloto" para el estudio que CEPAL-México quiere realizar posteriormente a nivel regional (Centroamérica y Caribe), en base, originalmente, a 100 encuestas cursadas a familias con parientes en los Estados Unidos, que residen en un barrio popular en la periferia de la ciudad de Santa Tecla, cabecera del Departamento de La Libertad, y bastante cercano a San Salvador; sus habitantes trabajan como obreros, empleados de bajo nivel, motoristas de autobuses y taxis, maestras, enfermeras y similares - fuera de la alta tasa de desempleo y subempleo, fenómeno predominante en el país. Se elaboró una encuesta con más de 100 variables, que fue revisada por el equipo de investigadores y asesores, probada con personas de características similares a las que se encuestaria luego, ajustada y reproducida para cursarla. La premura del corto tiempo disponible para la investigación forzó a tomar decisiones rápidas y a utilizar recursos extraordinarios de personas y tiempos para cursar las encuestas, procesar los datos y analizar los resultados, a fin de cumplir en el breve plazo disponible.

Para conocer mejor el fenómeno y sus implicaciones, optamos por dividir la muestra en tres submuestras principales: 1) urbano pobre (habitantes del mencionado barrio popular en Santa Tecla); 2) urbano marginal (en un barrio marginal, extremadamente pobre, ubicado en la periferia de San Salvador, conocido como "La Chacra"); 3) rural: en un comienzo se cursaron encuestas en una aldea ("Los Sitios") del municipio de Jayaque en el Departamento de La Libertad, pero al advertir que no todas las familias eran estrictamente "rurales", porque unas trabajan en empresas avicolas o en agroindustrias del caté, y otras carecen de tierra para cultivar, se decidió cursar otra parte en el cantón "Casitas", del municipio de Texistepeque, Departamento de Santa Ana, población estrictamente rural y de características peculiares por el hecho de que todas las familias tienen parientes en los Estados Unidos y viven básicamente de las remesas que reciben, como se analizó en la investigación citada (Montes, 1987, 174-178). En consecuencia, no se trata de muestras aleatorias, sino de selección intencional, en lugares escogidos previamente por sus características, y se encuestó únicamente a familias con parientes en los Estados Unidos que reciben remesas de ellos. Las encuestas se cursaron en la última semana de junio y primera de julio. 


\section{Análisis de los datos}

\section{I.1. Característlcas de la familla residente en EI Salvador}

En el CUADRO 1 se presentan los datos de la muestra y submuestras:

\section{CUADRO 1}

Personas encuestadas, por sexo y grupo

(en valores absolutos y en \% simple)

\begin{tabular}{lrrrrrrrr}
\hline Categoria & $\begin{array}{c}\text { Muesira } \\
\text { Total }\end{array}$ & $\begin{array}{c}\text { urb. } \\
\text { pobre }\end{array}$ & $\begin{array}{c}\text { urb. } \\
\text { marg. }\end{array}$ & rural & Casltas & \multicolumn{2}{c}{$\begin{array}{c}\text { Jefe de familla } \\
\text { varón }\end{array}$} & mujer \\
\hline Mascul. & $29-25.7 \%$ & $7-18.4$ & $9-23.1$ & $13-36.1$ & $8-36.4$ & $25-46.3$ & $4-6.8$ \\
Femen. & $84-74.3 \%$ & $31-81.6$ & $30-76.9$ & $23-63.9$ & $14-63.6$ & $29-53.7$ & $55-93.2$ \\
\hline TOTAL & $113-100 \%$ & $38-100 \%$ & $39-100 \%$ & $36-100 \%$ & $(22-100 \%)$ & $(54-100 \%)$ & $(59-100 \%)$ \\
& $(100 \%)$ & $(33.6 \%)$ & $(34.5 \%)$ & $(31.9 \%)$ & $((61.1))$ & $((47.8))$ & $((52.2))$ \\
\hline
\end{tabular}

Como se puede ver en el CUADRO 1, se ha cursado un total de 113 encuestas válidas, distribuidas asi: 38 en zona urbana pobre, 39 en zona urbana marginal y 36 en zona rural -de éstas 22 fueron cursadas en el cantón Casitas, y por eso su valor absoluto y porcentual está encerrado entre paréntesis, dado que no son encuestas distintas de las anteriores; algo similar ocurre con las columnas de "jefe de familia", que se refieren al total de la muestra. A pesar de que se intentaba encuestar al jefe de familia, sólo $25.7 \%$ de las encuestas fueron realizadas con varones, ya fuera porque es la mujer el jefe de familia, ya fuera porque el varón no se encontraba en la casa al momento de la encuesta; de todas maneras, como se ve en las dos últimas columnas, entre las familias encuestadas la mujer es el jefe de la familia en el $52.2 \%$ de los casos. En el CUADRO 2 se puede apreciar mejor la distribución de los jefes de familia, tanto por sexo en cada una de las submuestras, como por estado civil de ellos.

Con la excepción del sector rural, el jefe de familia actual es mayoritariamente la mujer; este hecho tal vez se pueda explicar, al menos en parte, en el sector "urbano pobre" como consecuencia de la migración a los Estados Unidos de un mayor porcentaje del esposo-compañero de vida, pero no para el resto de sectores, en los que esa categoria tiene valores muy similares, e incluso bastante superiores para el subsector "Casitas" (ver CUADRO 7, primera linea de parentesco del que envia remesas); más bien parece confirmar hallazgos de otras investigaciones sobre la familia salvadoreña, en los que se percibe mayor integración familiar en el campo que en barrios marginales urbanos, tanto más cuanto 


\section{CUADRO 2}

Qulén es el jefe de familla actual; por sexo y estado clvil (en \% simple)

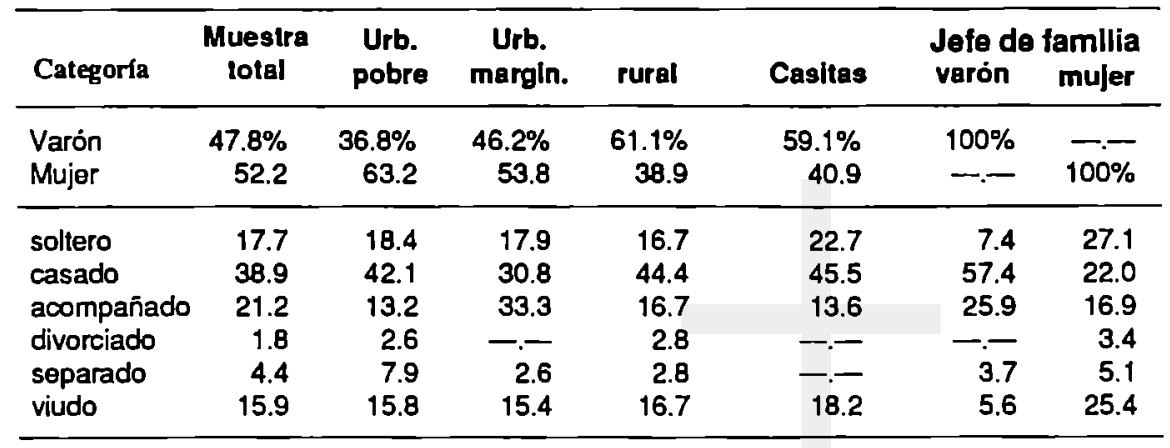

dispongan de alguna propiedad o medio estable de vida, trabajo e ingresos. Por lo que respecta al estado civil del jefe de familia, y con las variaciones que se advierten en cada grupo, la distribución por categorias no difiere significativamente del conjunto de la sociedad salvadorefia, salvo en el elevado porcentaje de "viudos" —y más entre las mujeres- que pudiera deberse a consecuencias de la guerra y la crisis del pais; el que haya un porcentaje tan elevado de jefes de familia que se reconocen como "solteros" tampoco es alarmante para los promedios nacionales $-y$ más en esos niveles sociales-, ya sea porque si no están casados suelen decirse "solteros", dándoles pena a muchos decirse "acompañados", o porque de hecho no lo estén en el presente.

En el CUADRO 3 se presenta los promedios de personas que viven juntas, desagregadas en dependientes por la edad (menores de 15 años y mayores de 65), dependientes porque no trabajan (desempleados) y dependientes de otro tipo (trabajadores familiares no remunerados, que trabajan en la parcela, negocio o taller, pero sin salario asignado).

Se puede apreciar que los promedios mayores, en todas la categorias, corresponden a la población urbana marginal y a los grupos en que el jefe de familia es mujer, lo que viene a deteriorar aún más las condiciones de vida de esos grupos familiares -el caso de Casitas es comprensible, dada la migración masiva a los Estados Unidos, con la consiguiente disminución de personas por familia. Si nos atenemos a la muestra total, la suma de todos los dependientes de cualquier naturaleza se eleva a 4.37, lo que indica que hay un promedio de 1.41 personas por familia que trabajan de alguna forma (menos de 1 por familia en Casitas) - si bien entre las mujeres es muy elevado el porcentaje de las que se dedican al hogar; de hecho, el total de dependientes cuando el jefe de 


\section{CUADRO 3}

Mlembros de la tamilla que viven juntos, por categorlas (medlas)

\begin{tabular}{|c|c|c|c|c|c|c|c|}
\hline Categoria & $\begin{array}{l}\text { Muostra } \\
\text { blal }\end{array}$ & $\begin{array}{l}\text { Urb. } \\
\text { pobre }\end{array}$ & $\begin{array}{c}\text { Urb. } \\
\text { margln. }\end{array}$ & rural & Caaltas & $\begin{array}{l}\text { Jefe de } \\
\text { varón }\end{array}$ & $\begin{array}{l}\text { amille } \\
\text { muler }\end{array}$ \\
\hline $\begin{array}{l}\text { Total viven } \\
\text { juntos }\end{array}$ & 5.78 & 5.13 & 6.80 & 5.36 & 4.32 & 5.36 & 5.92 \\
\hline \multirow{3}{*}{$\begin{array}{l}\text { Dependien- } \\
\text { tes por edad } \\
\text { Depen. porque } \\
\text { no trabajan } \\
\text { Dep.: trab. fam. } \\
\text { no remunerado }\end{array}$} & 2.46 & 1.90 & 2.92 & 2.56 & 1.96 & 2.24 & 2.66 \\
\hline & 1.70 & 1.66 & 1.92 & 1.50 & 1.27 & 1.65 & 1.75 \\
\hline & 0.21 & 0.11 & 0.33 & 0.19 & 0.14 & 0.19 & 0.24 \\
\hline Suma de los 3: & 4.37 & 3.67 & 5.17 & 4.25 & 3.37 & 4.08 & 4.65 \\
\hline
\end{tabular}

familia es mujer suma 4.65 , quedando nada más 1.27 personas que trabajan, de las que $20.3 \%$ lo hacen en "oficios del hogar", como se puede ver en el siguiente cuadro.

He dividido en cinco bloques las diversas categorías de trabajo de los jefes de familia. En el primero se incluye a los que no trabajan: que los que digan que no trabajan en nada se ciña a las mujeres - sectores urbano pobre y rural- puede sugerir que se ocupan de los oficios del hogar; los jubilados sin pensión y desempleados se concentran más en el sector urbano pobre; no hay jubilados pensionados ni en el sector rural ni en el sexo femenino - dato concordante con el hecho que para el campesinado no existe seguridad social ni jubilaciones remuneradas, y que las mujeres en esos niveles sociales tienen menos oportunidades de trabajos con derecho a jubiliación.

En el segundo bloque se incluyen los trabajos que se pueden considerar como del "sector formal" de la economía. El porcentaje para el total de la muestra alcanza al $39 \%$, pero con mayor peso en el sexo masculino que en el femenino, y con marcadas diferencias según sectores. La calidad de obrero se concentra mucho en el sector urbano marginal y en el sexo masculino, mientras la de empleado y profesor (a) en el urbano pobre -la última casi exclusivamente entre mujeres-, y la de jornalero agrícola sólo aparece en el sector rural y sexo masculino.

El tercer bloque lo constituyen ocupaciones que pueden ser una especie de puente entre el sector formal y el informal: los "transportistas" -que, por lo demás, sólo aparecen en el sector urbano marginaltambién se definen a si mismos, a veces, como "hacen viajes", lo que 


\section{CUADRO 4}

En qué trabaja el jefe de familla

(en \% simple)

\begin{tabular}{|c|c|c|c|c|c|c|c|}
\hline Categorfa & $\begin{array}{c}\text { Muesira } \\
\text { total }\end{array}$ & $\begin{array}{l}\text { Urb. } \\
\text { pobre }\end{array}$ & $\begin{array}{c}\text { Urb. } \\
\text { margln. }\end{array}$ & rural & Casitas & $\begin{array}{l}\text { Jefe de } \\
\text { verón }\end{array}$ & $\begin{array}{l}\text { lamilla } \\
\text { mujer }\end{array}$ \\
\hline $\begin{array}{l}\text { En nada } \\
\text { jubil.-desemp. } \\
\text { jubil. pensión }\end{array}$ & $\begin{array}{l}1.8 \% \\
8.0 \\
1.8\end{array}$ & $\begin{array}{c}2.6 \% \\
15.8 \\
2.6\end{array}$ & $\begin{array}{r}-.- \\
2.6 \\
2.6\end{array}$ & $\begin{array}{l}2.8 \% \\
5.6 \\
-.-\end{array}$ & $\begin{array}{r}-.5 \\
-.-\end{array}$ & $\begin{array}{r}-.- \\
9.3 \\
3.7\end{array}$ & $\begin{array}{c}3.4 \% \\
6.8 \\
-.-\end{array}$ \\
\hline 1. & $(11.6 \%)$ & $(21.0 \%)$ & $(5.2 \%)$ & $(8.4 \%)$ & $(4.5 \%)$ & $(13.0 \%)$ & $(10.2 \%)$ \\
\hline $\begin{array}{l}\text { mozo } \\
\text { obrero } \\
\text { choler } \\
\text { empleado } \\
\text { profesor (a) } \\
\text { jornal. agrlcol. }\end{array}$ & \begin{tabular}{r|}
3.5 \\
12.4 \\
4.4 \\
7.1 \\
7.1 \\
4.5
\end{tabular} & $\begin{array}{r}2.6 \\
5.3 \\
7.9 \\
18.5 \\
13.2 \\
-.-\end{array}$ & $\begin{array}{r}2.6 \\
23.1 \\
2.6 \\
2.6 \\
7.7 \\
-.-\end{array}$ & $\begin{array}{r}5.6 \\
8.3 \\
2.8 \\
-.- \\
1 .- \\
13.9\end{array}$ & $\begin{array}{r}4.5 \\
-.- \\
-.- \\
-\frac{1}{9.1}\end{array}$ & \begin{tabular}{r|}
5.6 \\
18.5 \\
5.6 \\
7.4 \\
1.9 \\
9.3
\end{tabular} & $\begin{array}{r}1.7 \\
6.8 \\
3.4 \\
6.8 \\
11.9 \\
-.-\end{array}$ \\
\hline 2 & $(39.0 \%)$ & $(47.5 \%)$ & $(38.6 \%)$ & $(30.6 \%)$ & $(13.6 \%)$ & $(48.3 \%)$ & (30.6\%) \\
\hline $\begin{array}{l}\text { transportista } \\
\text { agric. pequeño } \\
\text { comerciante }\end{array}$ & $\begin{array}{l}1.8 \\
8.0 \\
3.5 \\
\end{array}$ & $-\frac{-.-}{2.6}$ & $\begin{array}{l}5.1 \\
2.6 \\
2.6 \\
\end{array}$ & $\begin{array}{r}22.3 \\
5.6\end{array}$ & $\begin{array}{r}-.7 \\
31.7 \\
9.1\end{array}$ & $\begin{array}{r}1.9 \\
14.9 \\
5.6 \\
\end{array}$ & $\begin{array}{l}1.7 \\
1.7 \\
1.7 \\
\end{array}$ \\
\hline 3. & (13.3\%) & $(2.6 \%)$ & $(10.3 \%)$ & $(27.6 \%)$ & $(40.8 \%)$ & (22.4\%) & ( $5.1 \%)$ \\
\hline 4. ofic. hogar & $13.3 \%$ &.-- & $12.8 \%$ & $27.8 \%$ & $40.9 \%$ & $5.6 \%$ & $20.3 \%$ \\
\hline $\begin{array}{l}\text { artesano } \\
\text { sirv.-lavar } \\
\text { costurera } \\
\text { venta popular } \\
\text { ventas ambul. }\end{array}$ & $\begin{array}{l}4.4 \\
5.3 \\
2.7 \\
8.0 \\
2.7\end{array}$ & $\begin{array}{l}7.9 \\
5.2 \\
5.3 \\
7.9 \\
2.6\end{array}$ & $\begin{array}{r}5.1 \\
5.2 \\
2.6 \\
15.4 \\
5.1\end{array}$ & $\begin{array}{r}-. \overline{5.6} \\
-.- \\
-.- \\
-.-\end{array}$ & $\begin{array}{l}-.- \\
-.- \\
-.- \\
-.-\end{array}$ & $\begin{array}{r}7.4 \\
-.- \\
1.9 \\
1.9\end{array}$ & $\begin{array}{r}1.7 \\
10.2 \\
5.1 \\
13.6 \\
3.4\end{array}$ \\
\hline 5. & $(23.1 \%)$ & $(28.9 \%)$ & $(33.4 \%)$ & $(5.6 \%)$ & $(0.0 \%)$ & $(11.2 \%)$ & $(34.0 \%)$ \\
\hline TOTAL: & $100 \%$ & $100 \%$ & $100 \%$ & $100 \%$ & $100 \%$ & $100 \%$ & $100 \%$ \\
\hline
\end{tabular}

NOTA: Parece extraño que entre las mujeres jeles de familia aparezcan ocupaciones del jele de familia en "mozo, chofer y transportista", y entre los hombres "oficios del hogar". La explicación que se ve más lógica es que no hayan respondido bien a la pregunta de quien es el jefe de familia, o que sea algo ambigua esa responsabilidad.

propiamente es parte del sector informal, en la mayoria de los casos; los agricultores en pequeño, predominantes en el sector rural y en el sexo masculino, en muchos casos son productores de subsistencia -e incluso menos que eso-, y no siempre cultivan, dependiendo del acceso a la tierra, a créditos o fondos para insumos, mano de obra fuerte, entre otras cosas; en cuanto a los comerciantes -a pesar de que se los ha diferenciado de pequefios negocios y ventas ambulantes o caseras, en varios casos pertenecen al sector informal, y en otros al formal. Dejando de lado el bloque cuarto, correspondiente a "oficios del hogar", propio de 
mujeres, y tanto más representativo cuanto más rural o de menor nivel social $-y$ que indudablemente corresponde al sector informal de la economia-; en el quinto y último bloque se ha reunido a los distintos trabajos propios del "sector informal", que representa el $23.1 \%$ del total de la muestra, con más peso en el sexo femenino, casi ausente en el sector rural -inexistente en la fracción más estrictamente rural de Casitas-, y tanto mayor en lo urbano cuanto más bajo sea el nivel económico-social.

Cinéndonos a los dos bloques más definidos (el 2 y el 5), para el total de la muestra es algo mayor el trabajo en el sector formal que en el informal, con gran predominancia en el sexo masculino $-y$ lo contrario en el sexo femenino-, y con mayor peso en el sector ubano de más alto nivel en la muestra; en el sector rural, por el contrario, el sector informal es casi inexistente - sobre todo si no se considera como tal la categoría de pequeho agricultor, que tiene ahi gran ponderación. Por último, la categoría de oficios del hogar va incrementándose a medida que se desciende del sector urbano pobre al subgrupo de Casitas, ya sea por la escasez creciente de oportunidades de trabajo fuera del hogar, ya sea por la mayor presión hacia las tareas domésticas que no pueden ser encomendadas a otra personas -especialmente si fueran asalariadas-, o ya sea también por estimar suficiente el nivel de ingresos con la ayuda de las remesas que reciben de Estados Unidos - principalmente en el campo, y de manera peculiar en Casitas, lugar ya señalado de características especiales en este aspecto.

Una consecuencia lógica del nivel y calidad del trabajo del jefe de familia se halla en los ingresos mensuales que percibe, que en algunos casos se ven incrementados por los aportes monetarios de otros miembros del grupo familiar, y en todos ellos por las remesas recibidas de parientes en los Estados Unidos - como se verá en el CUADRO 8.

He dividido el CUADRO 5 en dos bloques: hasta 500 colones mensuales (US\$100), que es la cifra aproximada del salario mínimo vigente al momento de la encuesta (C. 18 diarios en la capital, 17 en ciudades del interior, 10-11 en trabajo agricola); y por encima de esa cantidad. Casi las dos terceras partes de la muestra dicen percibir lo del primer bloque, pero cerca de la cuarta parte del total afirma que no percibe nada; la diferencia es notoria según el sexo del jefe de familia, pero es todavia más marcada a medida que se desciende en los niveles socio-económicos —de izquierda a derecha del cuadro; a excepción del sector urbano marginal, en no ganar nada, pues no se pueden dar el lujo de no percibir ningún ingreso, por pequefo que sea, para poder sobrevivir en la ciudad donde necesitan dinero para adquirir incluso los alimentos, que no los pueden producir. Por lo que respecta al segundo bloque, se aprecia 


\section{CUADRO 5}

Cuánto gana al mes el jefe de familia

(en colones y en \% simple)

\begin{tabular}{|c|c|c|c|c|c|c|c|}
\hline Categorla & $\begin{array}{l}\text { Muestra } \\
\text { lotal }\end{array}$ & $\begin{array}{l}\text { Urb. } \\
\text { pobre }\end{array}$ & $\begin{array}{l}\text { Urb. } \\
\text { margln. }\end{array}$ & rural & Casitas & $\begin{array}{l}\text { Jefe de } \mathrm{f} \\
\text { varón }\end{array}$ & $\begin{array}{c}\text { familla } \\
\text { mujer }\end{array}$ \\
\hline c. 0.0 & 23.9 & 18.4 & 17.9 & 36.1 & 45.5 & 16.6 & 30.5 \\
\hline $1-100$ & 5.3 & 5.3 & 2.6 & 8.4 & 4.5 & 3. B & 6.8 \\
\hline $101-200$ & 9.8 & 2.6 & 12.9 & 13.9 & 9.1 & 9.3 & 10.2 \\
\hline $201-300$ & 9.7 & 5.2 & 15.4 & 8.4 & 4.5 & 7.5 & 11.9 \\
\hline $301-400$ & 5.3 & 5.2 & 5.1 & 5.6 & 9.0 & 5.6 & 5.1 \\
\hline $401-500$ & 10.7 & 13.2 & 10.3 & 8.3 & 9.1 & 9.3 & 11.9 \\
\hline C. $0-500$ & $(64.7 \%)$ & $(49.9 \%)$ & $(64.2 \%)$ & $(80.7 \%)$ & $(81.7 \%)$ & $(52.1 \%)$ & $(76.4 \%)$ \\
\hline $501-700$ & 9.8 & 10.5 & 13.0 & 5.6 & 4.5 & 14.9 & 5.1 \\
\hline $701-1000$ & 9.8 & 21.0 & 5.1 & 2.8 & 4.5 & 16.6 & 3.4 \\
\hline $1001-1500$ & 8.9 & 15.8 & 2.6 & 8.3 & 4.5 & 11.1 & 6.8 \\
\hline No sabe-N.R. & 7.1 & 2.6 & 15.4 & 2.8 & 4.5 & 5.6 & 8.5 \\
\hline media & 410.3 & 582.2 & 345.1 & 290.1 & 254.3 & 530.6 & 296.7 \\
\hline
\end{tabular}

las mejores posibilidades económicas del sector urbano pobre, con más acceso a trabajos algo mejor remunerados. La media de lo que gana al mes el jefe de familia, por otra parte, está comprendida en el primer bloque -a excepción del sector urbano pobre y cuando es varón-, como se analizará más adelante.

\section{CUADRO 6}

Propledad del medio de trabajo

(en \% ajustado)

\begin{tabular}{cccccccc}
\hline Categorla & $\begin{array}{c}\text { Muestra } \\
\text { lotal }\end{array}$ & $\begin{array}{c}\text { Urb. } \\
\text { pobre }\end{array}$ & $\begin{array}{c}\text { Urb. } \\
\text { margin. }\end{array}$ & rural & Casilas & $\begin{array}{c}\text { Jefe de familia } \\
\text { varón }\end{array}$ & mujer \\
\hline $\mathrm{Si}$ & 33.3 & 31.4 & 38.2 & 30.3 & 25.0 & 35.8 & 30.6 \\
$\mathrm{No}$ & 66.7 & 68.6 & 61.8 & 69.7 & 75.0 & 64.2 & 69.4 \\
\hline
\end{tabular}

EI CUADRO 6, por su parte, nos muestra que la propiedad del medio de trabajo sólo alcanza a una tercera parte de los jefes de familia, con mayor peso en el sector urbano marginal -economia informal- y en el sexo masculino que en el femenino; pero lo digno de notarse es que en el sector rural -y más aún en el subgrupo de Casitas - la propiedad del medio de trabajo desciende en porcentaje, lo que nos indica que una 
buena parte de los "pequeños agricultores" (CUADRO 4, bloque 3) no son propietarios de la tierra que cultivan.

\subsection{Características de los parientes emlgrados a los Estados Uni- dos}

En el CUADRO 7 se presentan los principales datos relativos a los parientes emigrados a los Estados Unidos. El primer bloque se refiere al promedio total de parientes en cada uno de los grupos. Los otros dos bloques solamente ofrecen el sexo y el parentesco del primer pariente citado por la persona encuestada, y que les envia remesas; se ha seleccionado nada más el primer caso, no sólo para simplificar el análisis, sino también en la creencia de que el primer pariente citado es para el encuestado el más importante —de hecho ahí están los de parentesco más próximo y la gama es más completa-, y ordinariamente, no siempre -en algunos pocos casos ese primer nombrado no les envia nada, a veces porque acaba de irse-, es el que le envia más dinero.

\section{CUADRO 7}

Parientes en USA (media); sexo y parentesco del 10 citado que envía \$ (en $\%$ simple)

\begin{tabular}{|c|c|c|c|c|c|c|c|}
\hline Categorla & $\begin{array}{l}\text { Muestra } \\
\text { total }\end{array}$ & $\begin{array}{l}\text { Urb. } \\
\text { pobre }\end{array}$ & $\begin{array}{l}\text { Urb. } \\
\text { margin. }\end{array}$ & rural & Casitas & $\begin{array}{l}\text { Jefe de } \\
\text { varón }\end{array}$ & $\begin{array}{l}\text { familia } \\
\text { mujer }\end{array}$ \\
\hline No Parientes & 3.21 & 4.21 & 2.26 & 3.19 & 3.73 & 3.76 & 2.71 \\
\hline $\begin{array}{l}\text { masculino } \\
\text { femenino }\end{array}$ & $\begin{array}{l}50.4 \% \\
49.6\end{array}$ & $\begin{array}{l}57.9 \% \\
42.1\end{array}$ & $\begin{array}{l}46.2 \% \\
53.8\end{array}$ & $\begin{array}{l}47.2 \% \\
52.8\end{array}$ & $\begin{array}{l}50.0 \% \\
50.0\end{array}$ & $\begin{array}{l}46.3 \% \\
53.7\end{array}$ & $\begin{array}{l}54.2 \% \\
45.8\end{array}$ \\
\hline \multicolumn{8}{|l|}{ esposo (a) } \\
\hline $\begin{array}{l}\text { comp(a) vida } \\
\text { padres }\end{array}$ & $\begin{array}{l}8.0 \% \\
2.7\end{array}$ & $\begin{array}{c}13.2 \% \\
5.3\end{array}$ & $\begin{array}{l}5.1 \% \\
2.6\end{array}$ & $\begin{array}{l}5.6 \% \\
-.-\end{array}$ & $\begin{array}{l}9.1 \% \\
--.\end{array}$ & $\begin{array}{l}9.3 \% \\
1.9\end{array}$ & $\begin{array}{l}6.8 \% \\
3.4\end{array}$ \\
\hline hijos & 58.4 & 60.5 & 41.0 & 75.0 & 81.8 & 64.8 & 52.5 \\
\hline hermanos & 15.0 & 10.5 & 20.5 & 13.9 & 9.1 & 13.0 & 16.9 \\
\hline cuñados & 3.5 & 5.3 & 5.1 & - &.-- & 1.9 & 5.1 \\
\hline yerno-suegro & 0.9 & - - - & 2.6 & -.- & - - & 1.9 &.-- \\
\hline tio-primo-sob. & 11.5 & 5.3 & 23.1 & 5.6 & -.- & 7.4 & 15.3 \\
\hline
\end{tabular}

El total de la muestra arroja un promedio de 3.21 parientes emigrados a los Estados Unidos, con un peso mucho mayor en la población urbana pobre que en el resto, y elevándose en el sector rural, donde Casitas puede sesgar la ponderación, por ser un caso especial, como ya se ha 
indicado. De todos modos, sí parece claro que la cantidad de parientes emigrados está condicionada por las posibilidades económicas del grupo familiar, por lo que tanto en el sector urbano marginal como en los casos en que es la mujer la jefe de familia, los recursos para costear el viaje son menores, y a pesar de que les sería más necesario que algún miembro emigrara y les enviara remesas, sin embargo esa alternativa se les hace también muy difícil.

La distribución de los emigrados por sexo es muy similar en la muestra total, y en Casitas paritaria; predominan los hombres en el sector urbano pobre y cuando el jefe actual de la familia es la mujer - posiblemente en parte debido a la migración mayor del varón-; mientras que en el urbano marginal y en el rural hay mayoría de mujeres emigradas - posiblemente por la mayor disponibilidad a ocupar trabajos de servicio y limpieza-, y también cuando el jefe de familia es varón.

En cuanto al parentesco, resalta notoriamente la predominancia de los hijos, en todos los grupos -lo que refuerza la percepción de que es un mecanismo de ascenso económico y de asegurar una más cómoda ancianidad a los padres y un medio para criar y educar a los niños. En segundo lugar se encuentran los hermanos de los encuestados -que en muchos casos refleja el esfuerzo familiar para que uno de los miembros pueda emigrar y con las remesas beneficiarse o subsistir los demás. Pero también es de interés ver el relativamente elevado porcentaje de esposos-companeros de vida, fenómeno que, por un lado, muestra la urgencia de buscar desesperadamente medios de subsistencia, pero, por otro lado, previsiblemente incidirá en la desintegración $\longrightarrow$, al menos, debilitamiento de los vínculos de la familia.

\subsection{Impacto económico de las remesas y del pago del vlaje, en la fa- milla residente en El Salvador}

La crítica situación económico-social y laboral de la población encuestada ya se ha podido apreciar en los datos anteriores. Una salida que se les ha presentado frente a su precaria situación es realizar enormes sacrificios y esfuerzos para que alguno de los miembros de la familia pueda emigrar a los Estados Unidos. El esfuerzo, desde un punto de vista exclusivamente económico, ha valido la pena en la mayoria de los casos.

La primera categoría del CUADRO 8 nos muestra los ingresos promedio del jefe de familia, que está comprendido en el bloque inferior de salarios con la excepción del sector urbano pobre y del jefe de familia varón, que apenas lo superan-, con niveles progresivamente inferiores a medida que se desciende en la escala económico-social-urbano pobre a rural. Gracias al trabajo remunerado de algún otro miembro de la familia, 


\section{CUADRO 8}

Ingresos mensuales de las famillas, por nubros y relaclones (medias; en colones)

\begin{tabular}{|c|c|c|c|c|c|c|c|}
\hline \multirow[b]{2}{*}{ Categoria } & \multirow{2}{*}{$\begin{array}{l}\text { Muestra } \\
\text { lotal }\end{array}$} & \multirow{2}{*}{$\begin{array}{l}\text { Urb. } \\
\text { pobre }\end{array}$} & \multirow{2}{*}{$\begin{array}{c}\text { Urb. } \\
\text { margln. }\end{array}$} & \multirow[b]{2}{*}{ rural } & \multirow[b]{2}{*}{ Cesitas } & \multicolumn{2}{|c|}{ Jefe de familla } \\
\hline & & & & & & varón & mujer \\
\hline $\begin{array}{l}\text { 1. Ingreso } \\
\text { jefe de lam. }\end{array}$ & 410.30 & 582.16 & 345.06 & 290.14 & 245.29 & 530.63 & 296.67 \\
\hline $\begin{array}{l}\text { 2. Ingr. fam. } \\
\text { por trabajo }\end{array}$ & 754.77 & 1010.27 & 688.09 & 547.54 & 486.67 & 895.14 & 622.20 \\
\hline $\begin{array}{l}\text { 3. Remesas: } \\
\text { (US\$). } \\
(\times 5.4)=C\end{array}$ & $\begin{array}{l}(123.94) \\
669.28\end{array}$ & $\begin{array}{c}(145.40) \\
785.16\end{array}$ & $\begin{array}{c}(98.46) \\
531.68\end{array}$ & $\begin{array}{c}(128.89) \\
696.01\end{array}$ & $\begin{array}{c}(125.46) \\
677.48\end{array}$ & $\begin{array}{c}(105.00) \\
567.00\end{array}$ & $\begin{array}{c}(141.27) \\
762.86\end{array}$ \\
\hline $\begin{array}{l}\text { 4. Ingr. lam. } \\
\text { total }(2+3)\end{array}$ & 1424.05 & 1795.43 & 1219.77 & 1243.55 & 1164.15 & 1462.14 & 1385.06 \\
\hline $\begin{array}{l}\text { 5. \% remesas/ } \\
\text { ing. fam (3/2) }\end{array}$ & 88.67 & 77.72 & 77.27 & 127.12 & 139.21 & 63.34 & 122.61 \\
\hline $\begin{array}{l}\text { 6. \% remesa) } \\
\text { ing. lotal }(3 / 4)\end{array}$ & 47.00 & 43.73 & 43.59 & 55.97 & 58.19 & 38.78 & 55.08 \\
\hline
\end{tabular}

NOTA: La coincidencia no es exacta en las sumas, porque hay algunos casos de "missing values" en alguno de los grupos (ingreso del jefe de familia $=0.0$ ), modificando con ello ligeramente las medias.

el promedio del ingreso familiar mensual se eleva en una cantidad apreciable - guardando las mismas características por grupo que en la categoria anterior. La cantidad de dinero enviado a cada familia, en promedio, a través de las remesas de parientes en los Estados Unidos, supera al ingreso del jefe de familia, como se puede apreciar comparando la tercera - en colones - con la primera categoria; e incluso en varios casos, supera también al ingreso familiar mensual -quinta categoria-, con destacada predominancia en el sector rural, en familias en que el jefe es la mujer - posiblemente los emigrados del sector urbano marginal tienen menos oportunidades de trabajo en los Estados Unidos, o su ocupación es tan mal retribuida que apenas pueden enviar cantidades significativas a sus familiares, profundizando aún más con ello las diferencias con el resto de los grupos. Si se suman todos los ingresos familiares (del jefe de familia, de otros miembros, y las remesas recibidas de parientes en los Estados Unidos), la proporción que representan las remesas en todo el conjunto (categoría 6) se aproxima a la mitad para el total de la muestra, con mayor peso en el sector rural y en familias 
en las que el jefe es la mujer. Finalmente, los resultados obtenidos en esta investigación (categorías 3 y 6) confirman los datos logrados en la anterior, y le confiren mayor credibilidad a ambos (Montes, 1987, 113, CUADRO XII).

La forma en que cubrieron los gastos para que algún miembro de la familia emigrara a los Estados Unidos se puede apreciar en el CUADRO 9.

\section{CUADRO 9}

Pago de vlaje a USA; st se desprendleron de blenes, de cuáles (en \% simple el primer bloque, en $\%$ ajustado el segundo)

\begin{tabular}{|c|c|c|c|c|c|c|c|}
\hline Categorfa & $\begin{array}{l}\text { Mueatra } \\
\text { total }\end{array}$ & $\begin{array}{l}\text { Urb. } \\
\text { pobre }\end{array}$ & $\begin{array}{c}\text { Urb. } \\
\text { margln. }\end{array}$ & rural & Casltas & $\begin{array}{l}\text { Jefe de } \\
\text { varón }\end{array}$ & $\begin{array}{l}\text { Iamllla } \\
\text { mujer }\end{array}$ \\
\hline $\begin{array}{l}\text { Préstamo } \\
\text { Ayuda de USA } \\
\text { Ayuda parien. } \\
\text { Venta bienes } \\
\text { Ahorros } \\
\text { Indemni. traba. } \\
\text { No responde }\end{array}$ & $\begin{array}{c}57.5 \% \\
6.2 \\
3.5 \\
7.1 \\
19.5 \\
4.4 \\
1.8\end{array}$ & $\begin{array}{c}60.5 \% \\
2.6 \\
5.3 \\
7.9 \\
15.8 \\
5.3 \\
2.6\end{array}$ & $\begin{array}{r}46.2 \% \\
15.4 \\
2.6 \\
10.3 \\
20.5 \\
2.6 \\
2.6\end{array}$ & $\begin{array}{c}66.7 \% \\
-.- \\
2.8 \\
2.8 \\
22.2 \\
5.6 \\
-.-\end{array}$ & $\begin{array}{l}59.1 \% \\
-. \overline{4.5} \\
-. \overline{-} \\
36.4 \\
-.- \\
-.-\end{array}$ & $\begin{array}{c}64.8 \% \\
3.7 \\
5.6 \\
5.6 \\
16.7 \\
1.9 \\
1.9\end{array}$ & $\begin{array}{c}50.8 \% \\
8.5 \\
1.7 \\
8.5 \\
22.4 \\
6.8 \\
1.7\end{array}$ \\
\hline $\begin{array}{l}\text { Casa } \\
\text { Vehiculo } \\
\text { Negocio } \\
\text { Tierra } \\
\text { Mueb.-apar.el. } \\
\text { Anim.-prod.agr. }\end{array}$ & $\begin{array}{r}28.6 \\
9.5 \\
14.3 \\
14.3 \\
9.5 \\
23.8\end{array}$ & $\begin{array}{r}16.7 \\
33.3 \\
33.3 \\
-. . \\
16.7 \\
-.-\end{array}$ & $\begin{array}{l}42.9 \\
.-. \\
14.3 \\
14.3 \\
-. .5 \\
28.6\end{array}$ & $\begin{array}{c}25.0 \\
-.- \\
-. .- \\
25.0 \\
12.5 \\
37.5\end{array}$ & $\begin{array}{l}20.0 \\
-.- \\
-. \overline{-} \\
40.0 \\
-. \overline{0} \\
40.0\end{array}$ & $\begin{array}{r}27.3 \\
18.2 \\
-.- \\
-.- \\
9.1 \\
45.5\end{array}$ & $\begin{array}{l}30.0 \\
-.- \\
30.0 \\
30.0 \\
10.0 \\
-.-\end{array}$ \\
\hline
\end{tabular}

El pedir prestado ha sido el recurso más generalizado en todos los grupos - a veces, como expresan, dejando en prenda o hipoteca algún bien o título de propiedad-; para los que tienen menos crédito, la ayuda de otros parientes que ya habian emigrado con anterioridad, o del grupo familiar en El Salvador, viene a complementar las posibilidades. La venta de algunos bienes representa un porcentaje muy reducido; sin embargo, la categoría de "ahorros" puede ser algo ambigua para los encuestados, y contemplar tanto ahorros en dinero u otros bienes fácilmente negociables, en ayuda recibida de parientes en los Estados Unidos y que reservan para el pago del viaje de otro miembro de la familia, o en propiedades que no las consideren como tales (casa, animales, etc.) -como sugiere el grupo de Casitas, que no tiene ningún valor en la categoria de venta de bienes, pero si en tres rubros del segundo bloque (casa, 
tierra, animales y producción agrícola). También llama la atención el que existan casos de "indemnización en el trabajo", que al ser despedidos, o pedir indemnización o "antigüedad" al retirarse, destinan esos fondos para costear el viaje a los Estados Unidos, ya sea que lo hubieren planeado asi y por eso dejan el trabajo, ya sea que al quedar sin ocupación buscan la alternativa de la emigración.

Para los pocos casos que se han desprendido de bienes con el objetivo de pagar el viaje a los Estados Unidos de algún familiar, se ha diferenciado en los posibles rubros o categorias que aparecen en el segundo bloque del CUADRO 9. Es sencilla y fácilmente comprensible la diversidad en cada grupo, de acuerdo a sus medios de vida y nivel; pero en el sector urbano marginal los datos parecen confirmar su origen y extracción rural, su reciente migración a la ciudad y, consiguientemente, haberse desprendido de los pocos bienes que tenian en el campo, tanto para emigrar a la ciudad, como para poder subsistir mejor con la ayuda de las remesas que envien los parientes emigrados a los Estados Unidos, para lo cual, al menos en parte, se desprendieron de tales bienes.

\subsection{Impacto soclo-económico de la migración y las remesas}

Una de las preguntas claves de la investigación es el impacto que tiene la migración y las remesas recibidas, tanto en la mejoria del nivel de vida como en la inversión productiva y mejora de las condiciones y medios de trabajo. En los siguientes CUADROS se podrá medir estos fenómenos.

En el CUADRO 10 se han agrupado, en el primer bloque, las categorlas relacionadas con gastos de subsistencia y consumo. Son muy pocos los que no destinan nada a la alimentación, y el promedio de las remesas que dedican a eso supera el $50 \%$ - menos el sector urbano pobre, de mejor nivel, y que destina porcentajes comparativamente superiores a los otros rubros, de acuerdo a sus aspiraciones y posibilidades. Al pago y compra de casa los del sector umano marginal le dedican poco o ningún fondo, lo primero por ocupar terrenos públicos en su mayoria, lo segundo por no vislumbrar posibilidades reales de comprar una casa propia; en cuanto al sector rural, el caso suele ser que la casa ya es propia, por precaria que sea. La salud y compra de medicinas también absorbe una parte importante de las remesas, asi como la compra de ropa y calzado, lo mismo que la educación de los niños; todo ello dirigido a mejorar las condiciones de vida y la capacitación de la siguiente generación: los hijos de los emigrados.

El segundo bloque contiene los rubros o categorias vinculados con inversión productiva o medios de trabajo e ingreso. Como se aprecia claramente en el mismo cuadro, en todos los rubros superan al $90 \%$ las 


\section{Destino de las remesas de \$, por rubros (en \% simple para "nada"; y medla de lo que sI destinan)}

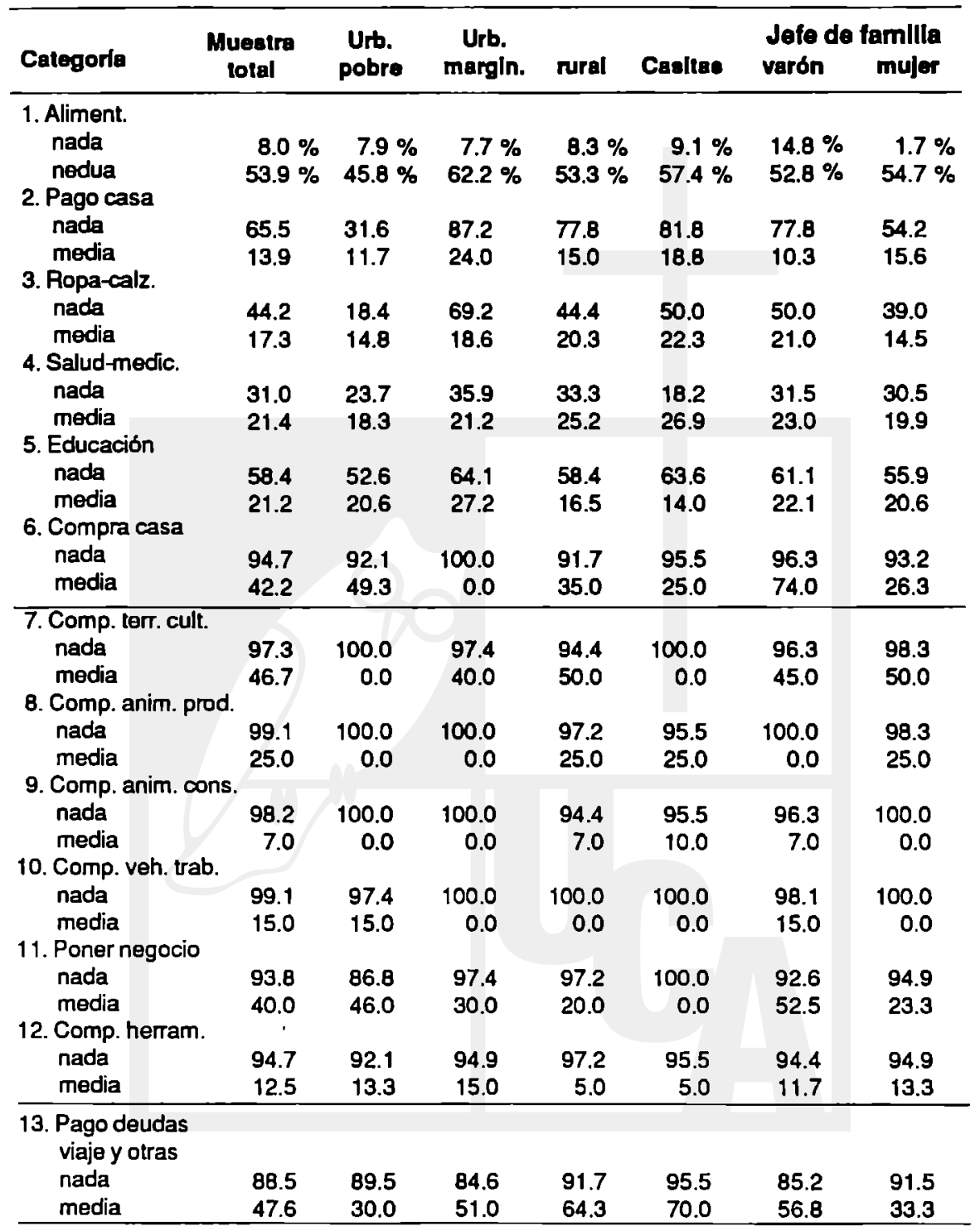

NOTA: La media está sacada únicamente entre las familias que destinan alguna parte de las remesas a ese rubro concrelo, excluyendo las que no destinan nada al mismo. 
familias que no dedican nada a ello, consumiendo casi todo lo obtenido a través de las remesas en gastos de subsistencia; si bien es cierto que por lo general las familias que destinan parte de las remesas a la inversión, asignan porcentajes relativamente altos. La diversidad de rubros y categorías clasifica a los distintos grupos o sectores y sus posibilidades de inversión: agropecuaria en el campo -la categoría 9 "compra de animales para el consumo" a veces se destinará al consumo familiar, y otras veces para el mercado-, y de negocios y conexos en lo urbano -predominantemente en el "sector informal" de la economía.

Finalmente se ha separado la última categoria (13), dado que existe un no despreciable porcentaje -infimo para el sector rurał, que destina una elevada proporción de las remesas para cancelar las deudas -en algunos casos el $100 \%$ para pagar préstamos y otras deudas contraidas para costear el viaje, y todavía no saldadas-, u otro tipo de deudas que en esos niveles económico-sociales son elevadas y estrangulantes. En los siguientes cuadros veremos otros aspectos del mismo fenómeno.

\section{CUADRO 11}

SI vivian ahi antes de Irse los familiares a USA y enviarle \$;

sl habrian Ido a la actual casa sin esa ayuda (en \% ajustado)

\begin{tabular}{lrrrrrrr}
\hline Categoria & $\begin{array}{c}\text { Muesira } \\
\text { tolal }\end{array}$ & $\begin{array}{c}\text { Urb. } \\
\text { pobre }\end{array}$ & $\begin{array}{c}\text { Urb. } \\
\text { marg. }\end{array}$ & rural & Casitas & $\begin{array}{c}\text { Jefe de familia } \\
\text { varón }\end{array}$ & mujer \\
\hline $\begin{array}{l}\text { Vivian ahí: } \\
\text { sí } \\
\text { no }\end{array}$ & 85.7 & 89.5 & 81.6 & 86.1 & 90.9 & 87.0 & 84.5 \\
\hline $\begin{array}{l}\text { Si no vivian, } \\
\text { habrian ido: }\end{array}$ & 14.3 & 10.5 & 18.4 & 13.9 & 9.1 & 13.0 & 15.5 \\
\hline $\begin{array}{l}\text { si } \\
\text { no }\end{array}$ & 56.0 & 50.0 & 75.0 & 28.6 & -1.7 & 66.7 & 46.2 \\
\hline & 44.0 & 50.0 & 25.0 & 71.4 & 100.0 & 33.3 & 53.8 \\
\hline
\end{tabular}

En la mayoría de los casos la familia ya vivia en el mismo lugar que ahora, desde antes de emigrar a Estados Unidos algún pariente -en menor proporción en el sector urbano marginal, acorde con datos anteriores. Sin embargo, de los que no vivian ya ahi, cerca de la mitad no habrian podido ir si no hubiera sido por la ayuda recibida a través de las remesas - hecho particularmente sobresaliente en el sector urbano marginal, y muy débil en el sector rural que tiene mayor permanencia residencial. 


\section{CUADRO 12}

\section{SI consiguieron la casa graclas a los $\$$ recibidos; qué medios de vida o de trabajo han adquirido con los $\$$ que les envian \\ (en \% ajustado)}

\begin{tabular}{|c|c|c|c|c|c|c|c|}
\hline Categoria & $\begin{array}{c}\text { Muestra } \\
\text { tolal }\end{array}$ & $\begin{array}{c}\text { Urb. } \\
\text { pobre }\end{array}$ & $\begin{array}{l}\text { Urb. } \\
\text { marg. }\end{array}$ & rural & Casltas & $\begin{array}{l}\text { Jefe de f } \\
\text { varón }\end{array}$ & $\begin{array}{l}\text { mllia } \\
\text { mujer }\end{array}$ \\
\hline $\begin{array}{l}\text { Consig. casa } \\
\text { con los } \$ \text { : } \\
\text { si } \\
\text { no }\end{array}$ & $\begin{array}{l}27.2 \\
72.8 \\
\end{array}$ & $\begin{array}{l}44.4 \\
55.6 \\
\end{array}$ & $\begin{array}{l}20.6 \\
79.4 \\
\end{array}$ & $\begin{array}{l}19.4 \\
80.6 \\
\end{array}$ & $\begin{array}{l}27.8 \\
72.2 \\
\end{array}$ & $\begin{array}{l}26.2 \\
73.8 \\
\end{array}$ & $\begin{array}{l}28.0 \\
72.0 \\
\end{array}$ \\
\hline $\begin{array}{l}\text { Medios adquir: } \\
\text { Vehlc. trabaj. } \\
\text { Herramient. } \\
\text { Capital trab. } \\
\text { Tienda-peq.neg. } \\
\text { Tierra cult. } \\
\text { Animales }\end{array}$ & $\begin{array}{r}6.3 \\
3.1 \\
9.4 \\
9.4 \\
12.5 \\
9.4\end{array}$ & $\begin{array}{r}12.5 \\
12.5 \\
12.5 \\
37.5 \\
-. \\
-\end{array}$ & $\begin{array}{r}12.5 \\
-. \overline{ } \\
25.0 \\
-. \overline{ } \\
25.0 \\
-.-\end{array}$ & $\begin{array}{l}-- \\
-- \\
-- \\
-.- \\
12.5 \\
18.8\end{array}$ & $\begin{array}{l}\text {-.- } \\
\text { - }- \\
-.- \\
-. \overline{-} \\
30.0\end{array}$ & $\begin{array}{r}5.6 \\
-.5 \\
5.6 \\
11.1 \\
16.7 \\
11.1\end{array}$ & $\begin{array}{r}7.1 \\
7.1 \\
14.3 \\
7.1 \\
7.1 \\
7.1\end{array}$ \\
\hline 1 & $(50.1 \%)$ & $(75.0 \%)$ & $(62.5 \%)$ & (31.3\%) & $(30.0 \%)$ & $(50.1 \%)$ & $(49.8 \%)$ \\
\hline $\begin{array}{l}\text { Casa } \\
\text { Mater. casa } \\
\text { Apar. eléct }\end{array}$ & $\begin{array}{l}12.5 \\
12.5 \\
15.6\end{array}$ & $\begin{array}{r}25.0 \\
-.- \\
-.-\end{array}$ & $\begin{array}{l}12.5 \\
12.5 \\
12.5\end{array}$ & $\begin{array}{r}6.3 \\
18.8 \\
25.0\end{array}$ & $\begin{array}{l}10.0 \\
30.0 \\
20.0\end{array}$ & $\begin{array}{r}16.7 \\
5.6 \\
16.7\end{array}$ & $\begin{array}{r}7.1 \\
21.4 \\
14.3\end{array}$ \\
\hline 2 & $(40.6 \%)$ & $(25.0 \%)$ & $(37.5 \%)$ & $(50.1 \%)$ & $(60.0 \%)$ & $(39.0 \%)$ & $(42.8 \%)$ \\
\hline $\begin{array}{l}\text { Cas/lote cult. } \\
\text { Mueb.-anima. } \\
\text { Casa-ganado }\end{array}$ & $\begin{array}{l}3.1 \\
3.1 \\
3.1\end{array}$ & $\begin{array}{l}-.- \\
-.-\end{array}$ & $\begin{array}{l}-.- \\
-.-\end{array}$ & $\begin{array}{l}6.3 \\
6.3 \\
6.3\end{array}$ & $\frac{--}{10.0}$ & $\begin{array}{r}5.6 \\
5.6 \\
-. \\
\end{array}$ & $-\frac{-.}{7.1}$ \\
\hline 3 & $(9.3 \%)$ & $(0.0 \%)$ & $(0.0 \%)$ & $(18.9 \%)$ & $(10.0 \%)$ & (11.2\%) & $(7.1 \%)$ \\
\hline TOTAL: & $(100 \%)$ & $(100 \%)$ & $(100 \%)$ & $(100 \%)$ & $(100 \%)$ & $(100 \%)$ & $(100 \%)$ \\
\hline
\end{tabular}

De los que respondieron que habian adquirido casa, la mayoria no la ha conseguido con las remesas que reciben de parientes en Estados Unidos - si bien en el sector urbano pobre el porcentaje afirmativo es elevado, como se puede ver en la primera parte del CUADRO 12. En la segunda parte del mismo cuadro se ha dividido en tres bloques: en el primero se han juntado los medios adquiridos con las remesas y que se refieren a inversión -mayormente en el "sector informal", como ya se vio- y que representa un porcentaje elevado, sobre todo en los sectores urbanos - si bien no hay que olvidar que son \% ajustados, y la mayoria no destina las remesas a inversión. En el segundo bloque se han 
reunido los rubros relacionados con mejoras en la vivienda -con mayor porcentaje en el sector rural. En el tercero se han juntado tres rubros o categorias que son mixtas, dado que, de acuerdo a las respuestas, algunas familias dicen haber destinado parte de las remesas a adquirir la casa y un pequefio lote de cultivo circundante, a modo de huerto, otras en muebles para la casa y animales, y otras dicen que han destinado fondos de las remesas a adquirir casa y ganado vacuno; de todos modos, este último bloque es exclusivo del sector rural, y para el caso de Casitas se destina tierra y dinero a ganadería en la zona. En conjunto, se aprecia que los niveles económico-sociales más bajos destinan mayor porcentaje de las remesas a mejorar las condiciones de vida y hogar, mientras que los de niveles menos bajos procuran invertir en algo productivo para lograr ocupación rentable y/o mejoras ulteriores.

\section{CUADRO 13}

Han mejorado las condiciones de vlda gracias a las remesas (sólo se toma la respuesta afirmatlva; en \% ajustado)

\begin{tabular}{lcccccccc}
\hline Categoria & $\begin{array}{c}\text { Muestra } \\
\text { total }\end{array}$ & $\begin{array}{c}\text { Urb. } \\
\text { pobre }\end{array}$ & $\begin{array}{c}\text { Urb. } \\
\text { marg. }\end{array}$ & rural & Casitas & varón & mujer \\
\hline $\begin{array}{l}\text { Vivienda } \\
\begin{array}{l}\text { Salud de } \\
\text { los niños }\end{array}\end{array}$ & 60.6 & 65.7 & 44.7 & 72.2 & 81.8 & 60.8 & 60.3 \\
$\begin{array}{l}\text { Alimentación } \\
\text { de niños }\end{array}$ & 64.6 & 67.9 & 56.8 & 70.6 & 80.0 & 62.5 & 66.7 \\
$\begin{array}{l}\text { Educación } \\
\text { de niños }\end{array}$ & 70.7 & 82.1 & 59.4 & 73.5 & 80.0 & 66.7 & 74.5 \\
\hline
\end{tabular}

Como se puede apreciar en el CUADRO 13, se contirman los datos relativos a la mejoria de las condiciones de vida, especialmente en los niños, por las remesas de dólares recibidos de los parientes en Estados Unidos. Es el sector urbano marginal el que menos se beneficia de hecho con las remesas, no sólo porque son menores, como se vio, sino por las condiciones concretas de los barrios marginales, si bien la educación es la más favorecida, buscando con ello mejorar en el futuro. En Casitas se aprecia un grupo peculiar, donde los padres han emigrado masivamente, y uno de los objetivos es asegurar mejor vida actual para sus hijos y prepararlos para el futuro, aquí o en los Estados Unidos. Por último, cuando el jefe de familia es la mujer, destina más recursos a mejorar la vida de los niños, lo que confirma también el menor acceso a ingresos propios para la subsistencia. 


\subsection{Camblos en la estructura famillar}

En la encuesta se buscaba detectar modificaciones en la estructura familiar, ya sea en la responsabilidad del hogar, en la unión de varios grupos familiares, o en el cambio del papel desempeñado por la mujer. En los siguientes cuadros se presentan los datos más relevantes obtenidos en la investigación.

\section{CUADRO 14}

Jefe de famllla: antes y después de Ir a USA esos familiares (en \% simple y ajustado: es el mismo)

\begin{tabular}{|c|c|c|c|c|c|c|c|}
\hline Categoría & $\begin{array}{c}\text { Muestra } \\
\text { total }\end{array}$ & $\begin{array}{l}\text { Urb. } \\
\text { pobre }\end{array}$ & $\begin{array}{l}\text { Urb. } \\
\text { marg. }\end{array}$ & rural & Casltas & $\begin{array}{l}\text { Jefe de } \\
\text { varón }\end{array}$ & $\begin{array}{l}\text { milla } \\
\text { muler }\end{array}$ \\
\hline \begin{tabular}{l}
\multicolumn{1}{c}{ antes: } \\
papá (esposo) \\
mamá (esposa) \\
abuelo (a)
\end{tabular} & $\begin{array}{r}54.9 \\
41.6 \\
3.5\end{array}$ & $\begin{array}{r}39.5 \\
55.3 \\
5.3\end{array}$ & $\begin{array}{r}59.0 \\
38.5 \\
2.6\end{array}$ & $\begin{array}{r}66.7 \\
30.6 \\
2.8\end{array}$ & $\begin{array}{r}63,6 \\
31.8 \\
4.5\end{array}$ & $\begin{array}{r}90.7 \\
7.4 \\
1.9\end{array}$ & $\begin{array}{r}22.0 \\
72.9 \\
5.1\end{array}$ \\
\hline $\begin{array}{l}\quad \text { ahora: } \\
\text { papá (esposo) } \\
\text { mamá (esposa) } \\
\text { abuelo (a) } \\
\text { hijo (a) } \\
\text { t'o (a) } \\
\text { ambos (papás) }\end{array}$ & $\begin{array}{r}39.8 \\
53.1 \\
4.4 \\
0.9 \\
0.9 \\
0.9\end{array}$ & $\begin{array}{r}21.1 \\
65.8 \\
7.9 \\
2.6 \\
2.6 \\
-.-\end{array}$ & $\begin{array}{r}43.6 \\
51.3 \\
2.6 \\
-.- \\
-.- \\
2.6\end{array}$ & $\begin{array}{r}55.6 \\
41.7 \\
2.8 \\
-.- \\
-.-\end{array}$ & $\begin{array}{r}50.0 \\
45.5 \\
4.5 \\
-.- \\
-.-\end{array}$ & $\begin{array}{r}79.6 \\
16.7 \\
1.9 \\
-.- \\
-. \overline{1.9}\end{array}$ & $\begin{array}{r}3.4 \\
86.4 \\
6.8 \\
1.7 \\
1.7 \\
-.\end{array}$ \\
\hline
\end{tabular}

El CUADRO 14 nos muestra el panorama más general y amplio. Predomina el varón como jefe de familia, menos en el sector urbano pobre, pero se detecta alguna incongruencia en las dos últimas columnas con el resto, especialmente en la última, donde se dice que la mujer es el jefe de familia; el porcentaje de abuelos como jefes de familia es bajo, pero importante. A consecuencia de la migración a los estados Unidos de algún miembro de la familia, en cambio, la dispersión es mayor, disminuyendo el porcentaje de los varones en todos los grupos, aumentando el de las mujeres también, asi como levemente los abuelos, y apareciendo las categorías de hijos y tíos, aunque sean minoritarias - los que dicen que ambos papás son jefe de la familia constituyen una cifra insignificante, reducida al sector urbano marginal y a los varones. En este aspecto, por consiguiente, ya se percibe algún cambio en la estructura y/o responsabilidad del hogar, al menos en lo relativo a quién se considera ser el jefe de familia $-y$ eso que no en todos los casos ha emigrado a los Estados Unidos precisamente uno de los progenitores del grupo. 
Responsable de los niños: antes y después de ir a USA esos famillares (en \% ajustado)

\begin{tabular}{|c|c|c|c|c|c|c|c|}
\hline Categorla & $\begin{array}{c}\text { Muestra } \\
\text { total }\end{array}$ & $\begin{array}{l}\text { Urb. } \\
\text { pobre }\end{array}$ & $\begin{array}{l}\text { Urb. } \\
\text { marg. }\end{array}$ & rural & Casitas & $\begin{array}{l}\text { Jefe de } \\
\text { varón }\end{array}$ & $\begin{array}{l}\text { millia } \\
\text { muler }\end{array}$ \\
\hline \begin{tabular}{l}
\multicolumn{1}{c}{ antes: } \\
papá (esposo) \\
mamá (esposa) \\
abuelo (a) \\
hermano (a) \\
ambos (papás)
\end{tabular} & $\begin{array}{r}14.6 \\
67.1 \\
6.1 \\
1.2 \\
11.0\end{array}$ & $\begin{array}{r}11.1 \\
63.0 \\
7.4 \\
-.7 \\
18.5\end{array}$ & $\begin{array}{r}9.7 \\
71.0 \\
9.7 \\
-. \overline{9.7}\end{array}$ & $\begin{array}{r}25.0 \\
66.7 \\
-.-1 \\
4.2 \\
4.2\end{array}$ & $\begin{array}{r}25.0 \\
66.7 \\
-.7 .3 \\
-.-\end{array}$ & $\begin{array}{r}28.6 \\
42.9 \\
2.9 \\
2.9 \\
22.9\end{array}$ & $\begin{array}{r}4.3 \\
85.1 \\
8.5 \\
-.-1 \\
2.1\end{array}$ \\
\hline $\begin{array}{l}\quad \text { ahora: } \\
\text { papá (esposo) } \\
\text { mamá (esposa) } \\
\text { abuelo (a) } \\
\text { hijo (a) } \\
\text { tlo (a) } \\
\text { ambos (papás) }\end{array}$ & $\begin{array}{r}10.5 \\
68.4 \\
11.8 \\
2.6 \\
2.6 \\
3.9\end{array}$ & $\begin{array}{r}-.- \\
68.0 \\
16.0 \\
4.0 \\
8.0 \\
4.0\end{array}$ & $\begin{array}{r}7.1 \\
75.0 \\
10.7 \\
3.6 \\
-.- \\
3.6\end{array}$ & $\begin{array}{r}26.1 \\
60.9 \\
8.7 \\
-.- \\
-.7\end{array}$ & $\begin{array}{r}27.3 \\
63.6 \\
9.1 \\
-.- \\
-. . \\
-.-\end{array}$ & $\begin{array}{r}25.0 \\
50.0 \\
9.4 \\
3.1 \\
3.1 \\
9.4\end{array}$ & $\begin{array}{r}-1 . \\
13.6 \\
2.3 \\
2.3 \\
\end{array}$ \\
\hline
\end{tabular}

EI CUADRO 15 nos revela otro aspecto de la responsabilidad familiar. Mayoritariamente se considera en la sociedad salvadoreña que los hijos son responsabilidad principal de la mamá, incluso en el caso en que convivan ambos progenitores; y es entre los varones, preferentemente en sectores urbanos $-y$ tanto más cuanto más elevado sea su nivel económico-social- donde la respuesta va en el sentido de mayor responsabilidad del papá o de ambos. Por efecto de la migración de algún miembro de la familia a los Estados Unidos se incrementa la responsabilidad de la mujer -en todos los sectores menos en el rural-, así como la de otros parientes.

Si ya predominaba el papel de la mujer en la administración del dinero en la casa, con la migración a los Estados Unidos se refuerza la tenencia, no siempre reconocida por los jefes de familia varones (CUADRO 16). Por último, el dinero resultante de las remesas recibidas de parientes en los Estados Unidos son mayoritariamente administradas por la mujer (CUADRO 17). Todo esto confirma el papel central que juega la mujer en el hogar y en la economía doméstica, que le confiere un poder y autoridad indiscutible, aun sin llegar al grado de un régimen matriarcal.

En los tres cuadros que siguen se trata de conocer un poco los efectos presentes y tendencias hacia el futuro, para los hijos y para la integración de la familia, cuando se han ido los padres, ambos o uno de ellos. 


\section{CUADRO 16}

Qulén administra dinero: antes y después de Ir a USA famillares (en \% simple y ajustado: es el mlsmo)

\begin{tabular}{|c|c|c|c|c|c|c|c|}
\hline Categoria & $\begin{array}{c}\text { Muestra } \\
\text { lotal }\end{array}$ & $\begin{array}{c}\text { Urb. } \\
\text { pobre }\end{array}$ & $\begin{array}{l}\text { Urb. } \\
\text { marg. }\end{array}$ & rural & Caslte8 & $\begin{array}{l}\text { Jefe de } \\
\text { varón }\end{array}$ & $\begin{array}{l}\text { milla } \\
\text { mujer }\end{array}$ \\
\hline \begin{tabular}{l}
\multicolumn{1}{c}{ antes: } \\
papa (esposo) \\
mamá (esposa) \\
abuelo (a) \\
ambos (papás)
\end{tabular} & $\begin{array}{r}24.8 \\
61.9 \\
5.3 \\
8.0\end{array}$ & $\begin{array}{r}18.4 \\
73.7 \\
5.3 \\
2.6\end{array}$ & $\begin{array}{r}23.1 \\
64.1 \\
7.7 \\
5.1\end{array}$ & $\begin{array}{r}33.3 \\
47.2 \\
2.8 \\
16.7\end{array}$ & $\begin{array}{r}36.4 \\
40.9 \\
4.5 \\
18.2\end{array}$ & $\begin{array}{r}42.6 \\
38.9 \\
3.7 \\
14.8\end{array}$ & $\begin{array}{r}8.5 \\
83.1 \\
6.8 \\
1.7\end{array}$ \\
\hline $\begin{array}{l}\quad \text { ahora: } \\
\text { papá (esposo) } \\
\text { mamá (esposa) } \\
\text { abuelo (a) } \\
\text { hijo (a) } \\
\text { tlo (a) } \\
\text { ambos (papás) }\end{array}$ & \begin{tabular}{r|}
17.7 \\
68.1 \\
5.3 \\
1.8 \\
1.8 \\
5.3
\end{tabular} & $\begin{array}{r}7.9 \\
76.3 \\
7.9 \\
2.6 \\
5.3 \\
-.-\end{array}$ & $\begin{array}{r}15.4 \\
74.4 \\
5.1 \\
2.6 \\
-.7 \\
2.6\end{array}$ & $\begin{array}{r}30.6 \\
52.8 \\
2.8 \\
-.- \\
1 .-\overline{13.9}\end{array}$ & $\begin{array}{r}31.8 \\
50.0 \\
-.- \\
-.- \\
.-.\end{array}$ & $\begin{array}{r}37.0 \\
44.4 \\
3.7 \\
1.9 \\
1.9 \\
11.1\end{array}$ & $\begin{array}{r}7 .- \\
89.8 \\
6.8 \\
1.7 \\
1.7 \\
-.-1\end{array}$ \\
\hline
\end{tabular}

\section{CUADRO 17}

Qulén administra los \$ que les envian de USA (en \% simple y ajustado: es el mismo)

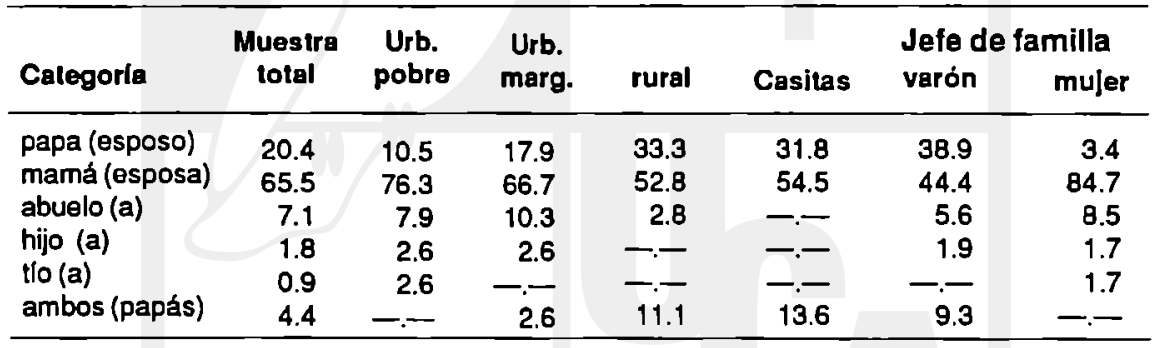

En el CUADRO 18 se presentan los datos para el caso de que hayan emigrado a los Estados Unidos ambos progenitores. Son los abuelos quienes se hacen cargo de los niños en muy elevado porcentaje -en algunos grupos, total. También se aprecia que la mayoria de los adultos no se lleva consigo a los hijos, ni piensa llevárselos - tenómeno comprensible por las consiguientes limitaciones para la vivienda, movilidad y trabajo remunerado; hecho coincidente con los datos obtenidos en la investigación anterior (Montes, 1987, 123-139). 


\section{CUADRO 18}

SI han Ido a USA ambos papás, sltuación de los hljos

(a partir de la segunda categorla sólo se toman respuestas aflrmativas) (en \% ajustado la primera categorla; las otras en \% simple)

\begin{tabular}{|c|c|c|c|c|c|c|c|}
\hline Categorla & $\begin{array}{c}\text { Muestra } \\
\text { lotal }\end{array}$ & $\begin{array}{l}\text { Urb. } \\
\text { pobre }\end{array}$ & $\begin{array}{l}\text { Urb. } \\
\text { marg. }\end{array}$ & rural & Caolta & $\begin{array}{l}\text { Jafe o } \\
\text { varón }\end{array}$ & $\begin{array}{l}\text { milla } \\
\text { mujer }\end{array}$ \\
\hline $\begin{array}{l}\text { Quién los cuida: } \\
\text { abuelo (a) } \\
\text { tlo (a) }\end{array}$ & $\begin{array}{l}86.7 \\
13.3\end{array}$ & $\begin{array}{l}80.0 \\
20.0\end{array}$ & $\begin{array}{l}85.7 \\
14.3\end{array}$ & $\begin{array}{c}100.0 \\
-.-\end{array}$ & $\frac{100.0}{-.}$ & $\begin{array}{c}100.0 \\
-.-\end{array}$ & $\begin{array}{l}80.0 \\
20.0\end{array}$ \\
\hline $\begin{array}{l}\text { Se los } \\
\text { llevaron: } \\
\text { Piensan } \\
\text { llevárselos }\end{array}$ & 15.0 & 15.8 & 17.9 & 11.1 & 13.6 & 16.7 & 13.6 \\
\hline
\end{tabular}

NOTA: Tanto en este cuadro como en los dos siguientes, los casos en que se cumplen las condiciones son pocos, pues la mayorla afirma haberse ido de jóvenes y solteros, o sin haber dejado hijos.

\section{CUADRO 19}

Si se fue solo el papá

(solo la respuesta afirmativa; en \% simple)

\begin{tabular}{|c|c|c|c|c|c|c|c|}
\hline Categoria & $\begin{array}{c}\text { Muestra } \\
\text { total }\end{array}$ & $\begin{array}{l}\text { Urb. } \\
\text { pobre }\end{array}$ & $\begin{array}{l}\text { Urb. } \\
\text { marg. }\end{array}$ & rural & Casltes & $\begin{array}{l}\text { Jefe de } \\
\text { yarón }\end{array}$ & $\begin{array}{l}\text { amilla } \\
\text { mujer }\end{array}$ \\
\hline \multirow{4}{*}{$\begin{array}{l}\text { Se llevó } \\
\text { algún hijo: } \\
\text { Piensa llevar } \\
\text { algún hijo: } \\
\text { Piensa llevar } \\
\text { todos los hijos: } \\
\text { Piensa llevar } \\
\text { madre de } \\
\text { sus hijos: }\end{array}$} & 4.4 & 2.6 & 7.7 & 2.8 & 4.5 & 3.7 & 5.1 \\
\hline & 5.3 & 2.6 & 7.7 & 5.6 & 4.5 & 3.7 & 6.8 \\
\hline & 4.4 & 2.6 & 7.7 & 2.8 & -.- & 3.7 & 5.1 \\
\hline & 3.5 & 5.3 & 5.1 &.-- & $-\ldots$ & 1.9 & 5.1 \\
\hline
\end{tabular}

EI CUADRO 19 nos revela el caso en que sólo ha emigrado el papá: son muy pocos los que se han llevado consigo algún hijo, piense llevarlos - alguno o todos- y mucho menos a la madre de sus hijos -es en el sector urbano marginal donde la incidencia positiva es algo mayor, pero siempre muy débil. En caso de que el papá no piense regresar, o no 
regrese de hecho, la desintegración familiar está ya en proceso, a no ser que al permanecer por tiempo largo cambie de actitud.

\section{CUADRO 20}

Si se fue sólo la mamá

(sólo la respuesta afirmativa; en \% simple)

\begin{tabular}{|c|c|c|c|c|c|c|c|}
\hline Categorla & $\begin{array}{l}\text { Muestra } \\
\text { total }\end{array}$ & $\begin{array}{c}\text { Urb. } \\
\text { pobre }\end{array}$ & $\begin{array}{l}\text { Urb. } \\
\text { marg. }\end{array}$ & rural & Casltas & $\begin{array}{l}\text { Jele o } \\
\text { varón }\end{array}$ & $\begin{array}{l}\text { milla } \\
\text { muler }\end{array}$ \\
\hline $\begin{array}{l}\text { Se llevó } \\
\text { algún hijo: } \\
\text { Piense llevar }\end{array}$ & 12.4 & 5.3 & 20.5 & 11.1 & 9.1 & 14.8 & 10.2 \\
\hline $\begin{array}{l}\text { algún hijo: } \\
\text { Piensa llevar }\end{array}$ & 17.7 & 10.5 & 23.1 & 19.4 & 18.2 & 18.5 & 16.8 \\
\hline $\begin{array}{l}\text { todos los hijos: } \\
\text { Piensa llevar } \\
\text { madre de }\end{array}$ & 16.8 & 10.5 & 23.1 & 16.7 & 9.1 & 18.5 & 15.3 \\
\hline sus hijos: & 5.3 & 5.3 & 2.6 & 8.3 & 9.1 & 7.4 & 3.4 \\
\hline
\end{tabular}

Cuando es la mamá el único progenitor que se fue, aumentan los porcentajes considerablemente en todos los grupos y categorias (CUADRO 20) -menos en la última para el sector urbano marginal, que parece sugerir una previa desintegración del núcleo familiar-, lo que ratifica no sólo la mayor vinculación afectiva de la mujer hacia el grupo familiar, sino que es ella la que nuclea dicho grupo. Ahora bien, aunque en menor grado que para el caso de que haya emigrado el papá, también aquí se manifiesta ya una desintegración de la familia, tanto más profunda y duradera cuanto más prolongada sea su ausencia - a no ser que, del mismo modo que para el varón, de alargarse su estancia en los Estados Unidos cambie de actitud.

En el CUADRO 21 se busca conocer si la migración a Estados Unidos ha producido algún tipo de concentración de familiares y reagrupamiento de las unidades en una especie de "familia extensa". En el primer bloque del cuadro se ve que son un bajo porcentaje los que han ido a vivir con otro grupo de parentesco, y éste predominantemente es muy cercano - no tanto en el sector rural. Más numeroso, aunque siempre minoritario, es el que la familia encuestada haya recibido a otros miembros de la familia -y no tan cercana siempre-, presumiblemente por la mayor disponibilidad de medios económicos y de subsistencia relativamente más desahogada.

Por último, se busca en el CUADRO 22 conocer algo sobre la modificación del papel de la mujer a consecuencia de la migración de algún miembro a los Estados Unidos, o al menos la percepción que ella 


\section{CUADRO 21}

Al Irse famillares a USA, han Ido a vivir con otros parientes, $u$ otros parlentes han Ido a vivir con los entrevistados

(en \% ajustado, parentesco; la otra categorla,

$\%$ simple; medla, ajustada)

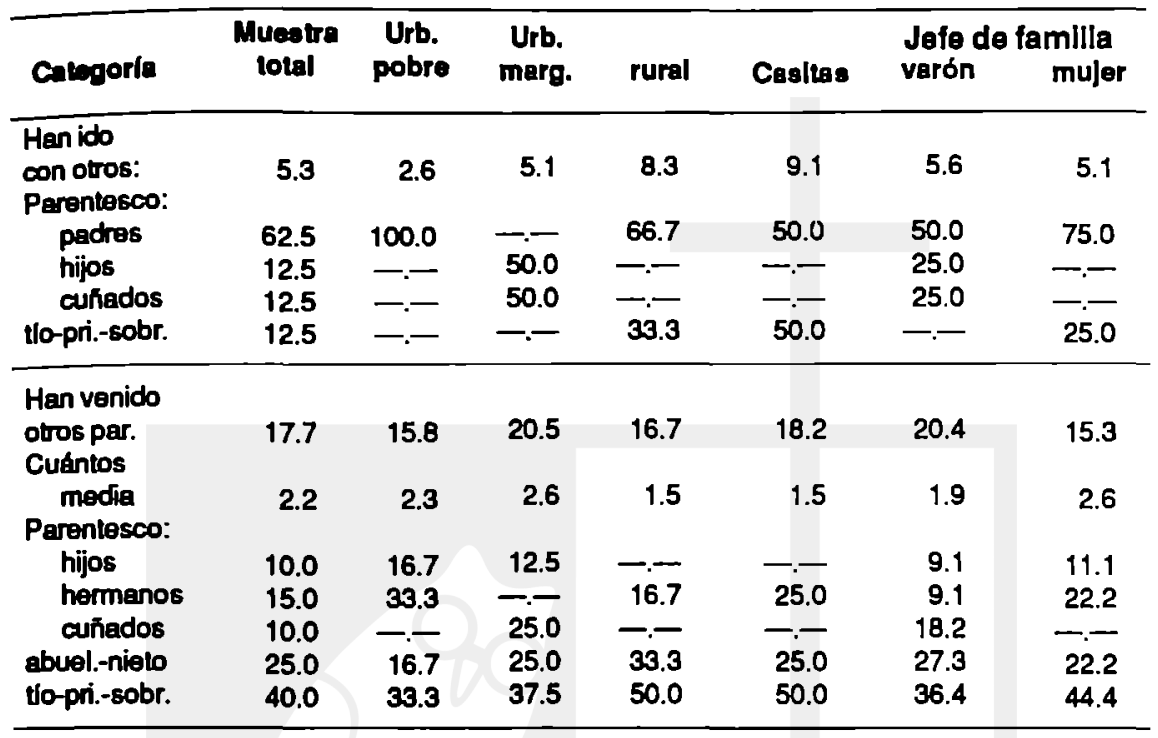

tiene de dicho fenómeno. Primero se presenta el cuadro general, total y desagregado; posteriormente se ofrecerán los datos más relevantes para el caso en que haya sido el esposo-companero de vida el emigrado a los Estados Unidos; para concluir diferenciando según quién de los dos era el jefe de familia antes de irse.

Algo más de una quinta parte, en promedio, dice que ha cambiado el papel de la mujer, resaltando el sector rural con mucho mayor peso que el resto. Fuera de los pocos casos - $20 \%$ del total, todos ellos en el sector nurał en que dicen que su situación ha mejorado, bien por tener menor responsabilidad sin los hijos, o bien por la mejora en su vida-, en todos los demás se ha incrementado su responsabilidad, ya sea como jefe de familia de hecho, ya sea por tener que cuidar de hijos propios y/o ajenos.

Ahora bien, si seleccionamos a las mujeres cuyos esposos-companeros de vida emigraron a los Estados Unidos y les envían dinero -que son los núcleos familiares con más garantía de integración familiar y responsabilidad del papá-, encontramos únicamente 7 casos $16.2 \%$ de la muestra total), 5 en el sector urbano pobre y 2 en el urbano mar- 
SI ha camblado, y en qué, el papel de la mujer al Ir a USA famlliares (en \% ajustado)

\begin{tabular}{|c|c|c|c|c|c|c|c|}
\hline Categorla & $\begin{array}{c}\text { Muestra } \\
\text { total }\end{array}$ & $\begin{array}{l}\text { Urb. } \\
\text { pobre }\end{array}$ & $\begin{array}{l}\text { Urb. } \\
\text { marg. }\end{array}$ & rural & Casltas & $\begin{array}{l}\text { Jefe de } \\
\text { varón }\end{array}$ & $\begin{array}{l}\text { mllla } \\
\text { mujer }\end{array}$ \\
\hline SI ha cambia. & 23.1 & 21.1 & 13.2 & 37.5 & 45.0 & 22.4 & 23.7 \\
\hline $\begin{array}{l}\text { Menos respons. } \\
\text { sin hijos } \\
\text { Ha mejorado }\end{array}$ & 4.0 &.-- & -- & 8.3 & - - & 9.1 &.-- \\
\hline $\begin{array}{l}\text { su vida } \\
\text { Respnsabilid. }\end{array}$ & 16.0 & -.- & -.- & 33.3 & 44.4 & 9.1 & 21.4 \\
\hline $\begin{array}{l}\text { total } \\
\text { se convirtio }\end{array}$ & 28.0 & 37.5 & 20.0 & 25.0 & 22.2 & 9.1 & -.- \\
\hline $\begin{array}{l}\text { en jefe lamil. } \\
\text { Más respon- }\end{array}$ & 4.0 & -.- & 20.0 & -- & - - & -.- & 7.1 \\
\hline $\begin{array}{l}\text { sabilidad } \\
\text { debe imponer }\end{array}$ & 32.0 & 50.0 & 20.0 & 25.0 & 22.2 & 72.7 & 42.9 \\
\hline $\begin{array}{l}\text { aut.-respeto } \\
\text { Más resp. con }\end{array}$ & 4.0 &.-- & 20.0 & -- & - & -.- & 7.1 \\
\hline $\begin{array}{l}\text { hijos ajenos } \\
\text { Cuidar hijos }\end{array}$ & B.0 & 12.5 & 20.0 &.-- & -.- & -.- & 14.3 \\
\hline prop. y ajenos & 4.0 &.-- & -.- & 8.3 & 11.1 & -.- & 7.1 \\
\hline
\end{tabular}

ginal; de ellas, 6 (el 85.7\%) dicen que si ha cambiado su papel $-33.3 \%$ por tener más responsabilidad, $50 \%$ por tener la responsabilidad total, y $16.7 \%$ porque tienen que imponer autoridad y respeto. Todo esto nos muestra que cuando es el padre de familia el que emigra, evidentemente se modifica el papel de la mujer, con mayor responsabilidad - a no ser que ya la tuviera total antes de la migración-, pero incluso en una buena cantidad de casos en que otro miembro de la familia fue quien emigró, también se fortalece y modifica el papel de la mujer, generando cambios sociales y sicológicos al interior del grupo familiar.

Cuando el jefe de familia era el varón antes de que alguno del grupo fuera a los Estados Unidos (57 casos del total), el papel de la mujer cambia, para toda la muestra, en un grado mayor al general $(29.8 \%)$, y se incrementa su responsabilidad en mayor grado en varias categorias. Por el contrario, cuando ya era la mujer el jefe de familia antes (47 casos del total), su cambio de papel sólo se produce en un $12.8 \%$ - grado bastante inferior al general-, mejorando su vida en un 33.3\% de los 6 casos. El cambio, por tanto, es mucho mayor en el papel que debe desempeñar la mujer en el hogar, y hacia una responsabilidad más plena, en el caso de grupos familiares mejor constituidos socialmente, al tener que ausentarse el varón. 


\subsection{Prevlsiones para el futuro del grupo famlllar y su desintegra- clón}

En los cuadros que siguen intentamos prever las consecuencias más durables de la desintegración familiar producida por la migración de alguno de los progenitores, primero del varón y luego de la mujer. En todas las categorias la pregunta básica es para los que dejaron hijos aqui al emigrar; en el primer bloque se pregunta si han abandonado del todo al grupo familiar, y se expresa en \% simple sólo en los casos afirmativos: en los demás bloques se pregunta por los mismos - hayan o no abandonado del todo al resto del grupo familiar-, como buscando indicadores de la desintegración permanente y futura.

\section{CUADRO 23}

Si fue sólo el varón que dejó hljos: consecuenclas famllares (en \% simple la primera categorla; en \% ajustado las demás)

\begin{tabular}{|c|c|c|c|c|c|c|c|}
\hline Categorla & $\begin{array}{c}\text { Muestra } \\
\text { tolal }\end{array}$ & $\begin{array}{l}\text { Urb. } \\
\text { pobre }\end{array}$ & $\begin{array}{l}\text { Urb. } \\
\text { marg. }\end{array}$ & rural & Casitas & $\begin{array}{l}\text { Jefe de } \\
\text { varón }\end{array}$ & $\begin{array}{l}\text { mille } \\
\text { mujer }\end{array}$ \\
\hline $\begin{array}{l}\text { Los abandonó } \\
\text { del todo }\end{array}$ & 2.7 & 2.6 & 2.6 & 2.8 & -- & -- & 5.1 \\
\hline $\begin{array}{l}\text { Esta acompañ. } \\
\text { en USA: } \\
\text { sí } \\
\text { no } \\
\text { no sabe }\end{array}$ & $\begin{array}{r}56.0 \\
40.0 \\
4.0\end{array}$ & $\begin{array}{r}40.0 \\
60.0 \\
-.-\end{array}$ & $\begin{array}{r}40.0 \\
60.0 \\
-.-\end{array}$ & $\begin{array}{l}80.0 \\
10.0 \\
10.0\end{array}$ & $\begin{array}{r}83.3 \\
16.7 \\
-.-\end{array}$ & $\begin{array}{r}58.3 \\
41.7 \\
-.-\end{array}$ & $\begin{array}{r}53.8 \\
38.5 \\
7.7\end{array}$ \\
\hline $\begin{array}{l}\text { Tiene otros } \\
\text { hijos en USA: } \\
\text { sl } \\
\text { no } \\
\text { no sabe }\end{array}$ & $\begin{array}{r}25.9 \\
70.0 \\
3.7\end{array}$ & $\begin{array}{r}18.2 \\
81.8 \\
-.-\end{array}$ & $\begin{array}{r}33.3 \\
66.7 \\
-.-\end{array}$ & $\begin{array}{l}30.0 \\
60.0 \\
10.0\end{array}$ & $\begin{array}{r}33.3 \\
66.7 \\
-.-\end{array}$ & $\begin{array}{r}33.3 \\
66.7 \\
-.-\end{array}$ & $\begin{array}{r}20.0 \\
73.3 \\
6.7\end{array}$ \\
\hline $\begin{array}{l}\text { Si regresara, } \\
\text { viviría con: } \\
\text { los de E.S. } \\
\text { los de USA }\end{array}$ & $\begin{array}{l}45.0 \\
55.0\end{array}$ & $\begin{array}{l}50.0 \\
50.0\end{array}$ & $\begin{array}{l}60.0 \\
40.0\end{array}$ & $\begin{array}{l}33.3 \\
66.7\end{array}$ & $\begin{array}{l}20.0 \\
80.0\end{array}$ & $\begin{array}{l}50.0 \\
50.0\end{array}$ & $\begin{array}{l}40.0 \\
60.0\end{array}$ \\
\hline
\end{tabular}

Son muy escasos los varones que han abandonado totalmente al grupo constituido antes de emigrar, y al menos les envian remesas de dinero con mayor o menor regularidad, por el momento. Si la encuesta está bien comprendida y bien respondida, es alarmante, no tanto el que estén acompañados en los Estados Unidos - suponiendo que con otra mujer distinta que en El Salvador-, cuanto el alto porcentaje que tiene otros hijos distintos alli $y$, peor aún, que una mayoría, o la mitad -a ex- 
cepción del sector urbano marginat en caso de regresar a El Salvador constituirla su hogar con el núcleo familiar formado en los Estados Unidos.

\section{CUADRO 24}

SI fue solo la mujer que dejó hljos: consecuenclas famlllares (en \% simple la primera; en \% ajustado las demás categorías)

\begin{tabular}{|c|c|c|c|c|c|c|c|}
\hline Categaria & $\begin{array}{c}\text { Muestra } \\
\text { total }\end{array}$ & $\begin{array}{l}\text { Urb. } \\
\text { pobre }\end{array}$ & $\begin{array}{l}\text { Urb. } \\
\text { marg. }\end{array}$ & rural & Casltas & $\begin{array}{l}\text { Jefe d } \\
\text { varón }\end{array}$ & $\begin{array}{l}\text { milia } \\
\text { mujer }\end{array}$ \\
\hline $\begin{array}{l}\text { Los abandonó } \\
\text { del todo }\end{array}$ & 2.7 &.-- & 5.1 & 2.8 & 4.5 & 3.7 & 1.7 \\
\hline \multicolumn{8}{|l|}{$\begin{array}{l}\text { Esta acompañ. } \\
\text { en USA: }\end{array}$} \\
\hline $\begin{array}{l}\text { sl } \\
\text { no }\end{array}$ & $\begin{array}{l}45.0 \\
50.0\end{array}$ & $\begin{array}{l}33.0 \\
66.7\end{array}$ & $\begin{array}{l}36.8 \\
52.6\end{array}$ & $\begin{array}{l}66.7 \\
33.3\end{array}$ & $\begin{array}{l}66.7 \\
33.3\end{array}$ & $\begin{array}{l}54.5 \\
36.4\end{array}$ & $\begin{array}{l}33.3 \\
66.7\end{array}$ \\
\hline no sabe & 5.0 & -.- & 10.5 & -.- & -.- & 9.1 &.-- \\
\hline \multicolumn{8}{|l|}{$\begin{array}{l}\text { Tiene otros } \\
\text { hijos en USA: }\end{array}$} \\
\hline $\begin{array}{l}\text { Si regresara, } \\
\text { vivirla con: } \\
\text { los de E.S. } \\
\text { los de USA } \\
\text { nuevo grupo }\end{array}$ & $\begin{array}{l}50.0 \\
25.0 \\
25.0\end{array}$ & $\begin{array}{r}66.7 \\
33.3 \\
-.\end{array}$ & $\frac{55.6}{4.4 .4}$ & $\begin{array}{l}30.0 \\
40.0 \\
30.0\end{array}$ & $\begin{array}{l}25.0 \\
25.0 \\
50.0\end{array}$ & $\begin{array}{l}33.3 \\
26.7 \\
40.0\end{array}$ & $\begin{array}{r}69.2 \\
23.1 \\
7.7\end{array}$ \\
\hline
\end{tabular}

Cuando ha sido la madre la que emigró dejando hijos no se ven diferencias en general con el caso del padre, en abandonarlos totalmente - salvo pequehas variaciones en los distintos grupos. Es menor, respecto al varón, la proporción de las que se afirma están acompañadas en los Estados Unidos, para todos los grupos; pero es mayor la proporción de las que tienen otros hijos distintos alli -tanto más cuanto se desciende en los niveles económico-sociales. Pero lo que merece consideración es que, si bien el porcentaje general de las que se reintegrarian al grupo familiar que tenian en El Salvador es algo mayor que para los varones - tanto más cuanto más elevado sea su nivel económico-social-, un porcentaje nada despreciable se cree que no se integraria ni al de El Salvador ni al constituido en los Estados Unidos, sino que formaria un tercero, nuevo.

De estos últimos datos parece concluirse que la mujer se mantiene como el vínculo familiar más consistente, comparando ambos progenitores; conserva más lazos afectivos y de reponsabilidad con los hijos, 
que el varón, en promedio; pero que la migración a los Estados Unidos también la afecta en profundidad, induciendo tendencias hacia una menor integración, o hacia la desintegración del grupo familiar. Siempre queda la duda de que haya sido mal entendida y respondida la pregunta, y que los encuestados se refieran a todos los emigrados -en su mayoría jóvenes, solteros y sin haber dejado hijos al irse-, no sólo a los que hayan dejado hijos aquí, y que las respuestas a si están o no acompanados, tienen otros hijos alli, y con qué grupo familiar se integrarian en caso de regresar se refieran a un conjunto más amplio que el de los que dejaron hijos al irse. Pero si la respuesta está en el sentido más estricto y riguroso, el problema de la desintegración familiar es importante, dado que entre los varones son $14(12.4 \%)$ los que están acompanados en los Estados Unidos, $7(6.2 \%)$ tienen otros hijos alli, y $11(9.7 \%)$ vivirían con ese grupo familiar si regresaran; entre las mujeres, $18(15.9 \%)$ están acompanadas, $13(11.5 \%)$ tienen otros hijos alli, $7(6.2 \%)$ vivirian con ese grupo familiar y otras $7(6.2 \%)$ con un nuevo si regresaran.

\subsection{Interrelaclón entre las remesas y otras varlables}

Se realizó un cruce entre la variable que expresa la cantidad de dinero que les envian sus parientes desde los Estados Unidos y todas las demás variables. Unicamente se encontró una correlación significativa, pero muy débil, con el estado civil del jefe de familia, con la mejoría en las condiciones de vida de los ninos (vivienda, salud, alimentación y educación), con la persona que administra las remesas, y con la cantidad de parientes que han venido a vivir con la familia encuestada al recibir ayuda de parientes en los Estados Unidos. Esto nos confirma que los niveles económicos de la población encuestada -que de alguna manera representa (no estadisticamente, en rigor, pero si prototípicamente) a la inmensa mayoria de la población del pais (ciertamente a más del $85 \%$ : Montes, 1979) - son tan precarios que se consumen en la adquisición de los bienes básicos e indispensables, mejorando un poco el nivel de vida, pero sin alcanzar a producir cambios cualitativos, en la mayor parte y proporción de los casos y remesas, a través de la inversión en medios productivos y rentables que les ayuden a salir de la situación de pobreza o miseria en que viven.

\section{Conclusiones}

El trabajo de investigación, como se indicó al inicio, no pretende ser representativo, sino válido para los encuestados, como estudio piloto en una muestra pequena y escogida intencionalmente. Subdividida la muestra en tres pequefios grupos - y uno de ellos en dos subgruposse perciben diferencias marcadas en los sectores a los que pertenecen, asi como también a las familias en las que el jefe es el varón, de aquellas 
en que es la mujer.

A pesar de que los grupos seleccionados se encuentran en el rango de la inmensa mayoría de la población salvadorena, están atrapados on una situación de pobreza que se refleja por la poca mano de obra capaz que puede trabajar, y esto en ocupaciones de bajo nivel y mal remuneradas, muchas de ellas del sector informal, y los medios y lugares de trabajo en su mayoría no son de su propiedad. Estos datos están bastante acordes con los de otras investigaciones recientes (Montes, 1988, 77-113, 132-170).

El porcentaje mayor de los emigrados a los Estados Unidos está en miembros cercanos de la familia nuclear, predominando los hijos, pero con una cantidad también apreciable de esposo(a)-compañero(a) de vida. Este hecho confirma también datos de otras investigaciones, en el sentido de que es la fuerza joven la que más emigra, como medio de obtener los recursos indispensables para la subsistencia de la familia y mejorar el nivel de vida, asi como para educar a los hijos y sostener a los padres en su ancianidad. La manera más generalizada de pagar ios elevados costos del viaje es pedir prestado, aunque algunos tienen que vender bienes, o reciben ayuda total o parcial de parientes, ya sea que estén en los Estados Unidos, o en El Salvador.

El impacto que tienen las remesas en la economla familiar es decisivo, e incluso en la mayoría de los casos es superior a todos los demás ingresos normales de la familia. Pero su situación de pobreza les obliga a que destinen la mayor parte del dinero de las remesas a completar los costos de supervivencia - mejorando, sin duda, las condiciones de vida, comparativamente-, y quedando muy poco disponible para ahorro e inversión productiva - que ordinariamente se ubica, cuando se da, en el "sector informal" de la economia, a no ser en lo rural donde se invierte a veces en algo más productivo y "formal", muchas veces de producción precaria. En los insignificantes casos de compra de tierras y/o de casa no se preguntó a nombre de quién estaban registradas; solamente en dos casos se nos dijo que la casa era para el miembro de la familia que estaba en los Estados Unidos, cuando regresara, como una especie de ahorro e inversión para vivir más cómodamente, pero no se explicó si la casa estaba a su nombre; dimos por supuesto que las demás casas y tierras adquiridas estarian inscritas a nombre del que hace de jefe de familia que se encuentra en EI Salvador, por razones legales y prácticas.

El papel de la mujer en el grupo familiar ha cambiado como consecuencia de la migración de alguno de los miembros a los Estados Unidos - tanto más si ése fue el esposo o companero de vida, y si ella no era ya desde antes el jefe de la familia-, pero no en el grado que se podia suponer, puesto que ya en un elevado porcentaje la mujer de 
hecho tiene grandes responsabilidades en el hogar y en muchos casos es el jefe de familia, en esos sectores económico-sociales - en menor proporción en el área rural donde la familia es más integrada y estable.

Finalmente, la desintegración familiar se produce por el simple hecho de la migración, especialmente si es el esposo (a)-compañero (a) de vida, o si alguno de los que se van dejan hijos. Pero lo más preocupante es el futuro de esos núcleos familiares desintegrados, a juzgar por los no pocos casos en que el emigrado está acompańado alli, tiene otros hijos distintos, y a su regreso no siempre piensan que se reintegrará al grupo familiar que dejó en El Salvador. En la medida que su permanencia alli se prolongue, habrá más probabilidad de una desintegración familiar definitiva.

\section{BIBLIOGRAFIA UTILIZADA}

Montes, Segundo: Estudlo sobre estratiflcaclón soclal en El Salvador; San Salvador, UCA, 1979.

Idem; El Salvador 1987. Salvadoreños reluglados en los Estados Unldos; San Salvador, UCA, Instituto de Investigaciones, 1987.

Idem y Meléndez, F., Palacios, E.; Los derechos económlcos, socla les y culturales en EI Salvador; San Salvador, UCA, Instituto de Derechos Humanos (IDHUCA), mayo de 1988. 